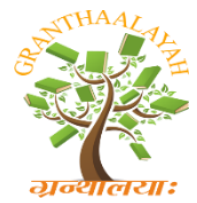

\author{
INTERNATIONAL JOURNAL OF RESEARCH - \\ GRANTHAALAYAH \\ A knowledge Repository
}

Social

\title{
INCREASING THE MOTIVATION OF PRIMARY SCHOOL PUPILS THROUGH THE USE OF ICT IN THE EDUCATIONAL PROCESS
}

\author{
Gencho Stoitsov *1, Gergana Stoitsova ${ }^{2}$ \\ ${ }^{* 1}$ Faculty of Mathematics and Informatics, University of Plovdiv Paisii Hilendarski, 24 Tzar \\ Asen, 4ooo Plovdiv, Bulgaria \\ 2 “Aleko Konstantinov” Primary School, 3A B. Zdravkov, 4ooo Plovdiv, Bulgaria
}

\begin{abstract}
This article presents a pedagogical study on the impact of Information Communication Technologies (ICT) on the motivation of primary school pupils in math classes. The obtained results demonstrate the positive impact of ICT on learning motivation.

Keywords: Learning Motivation; Motivation; Primary School; Information Communication Technologies; ICT; Mathematics; Education.

Cite This Article: Gencho Stoitsov, and Gergana Stoitsova. (2019). "INCREASING THE MOTIVATION OF PRIMARY SCHOOL PUPILS THROUGH THE USE OF ICT IN THE EDUCATIONAL PROCESS." International Journal of Research - Granthaalayah, 7(2), 207-213. https://doi.org/10.29121/granthaalayah.v7.i2.2019.1025.
\end{abstract}

\section{Introduction}

Motivation (Ilin, 2002) is at the root of every learning, provoked by the desire or the need to acquire new knowledge. Primary school pupils' motivation to learn is mainly being provoked by adults (teachers and parents) who seek to convince the child of the need for worthy educational efforts. The main prerequisites that motivate students to learn can be: a desire for learning, praise and fear of failure. At a later stage of education, with the increasing difficulty in different subjects, the majority of pupils experience a lower desire to learn and they find going to school annoying and obligatory. Therefore, it becomes necessary to seek and apply methodological solutions called innovative approaches that stimulate learning motivation (Koleva,Eredzhebova \& Moldovanova, 2016).

In many publications they comment on the role of e-learning resources (Staribratov \& Angelova, 2011), the application of cloud technologies in education (Zheleva, 2018), the importance of multimedia learning (Chipangura \& Aldridge, 2017), the positive influence of computer and mobile devices on student motivation (Nikou \& Economides, 2016). 
In our study, an attempt has been made to study the impact of selected digital approaches and learning content (Ivanova \& Velikova, 2015) on student motivation in math classes in primary school. The tools include: surveys; educational presentations; use of a specially developed electronic class system (Stoitsov \& Stoitsova, 2017), including electronic tests, e-learning content and electronic incentives.

\section{Evaluation of The Results from the Pedagogical Research}

During the academic years 2016/2017 and 2017/2018 a pedagogical study was carried out with a representative sample of 52 pupils from "Aleko Konstantinov" Primary School in Plovdiv, Bulgaria in order to establish a change in the level of pupils' motivation after using selected innovative approaches to training in the field of Information Communication Technologies (ICT).

\section{Methodology of the Study}

To carry out the study, two types of surveys were developed and used, containing a total of 10 questions:

- Initial motivation survey - 5 questions;

- Survey study of motivation in using ICT - 5 questions.

The research is aimed at identifying the impact of the selected innovative approaches in the field of ICT on the motivation of pupils from the elementary grades at "Aleko Konstantinov" Primary School. The questions included in the surveys cover the pupils' internal and external motivation (Gordeeva, Sychev \& Osin, 2014) and refer to the following groups:

- For internal motivation

1) Cognitive - diagnostics of the desire to learn the new subject matter, stimulated by pleasure and interest in knowledge;

2) Achievement - measures the pursuit of maximum high result, the pleasure of solving difficult tasks;

3) Self-development - measures the quest to develop personal abilities and potential within the learning activity, reaching a sense of competence.

- For external motivation

1) Self-esteem - measures the desire for learning, for self-importance and increased selfesteem in learning achievement. Need for respect and self-esteem.

2) Consideration of society - measures the need for educational activities related to the needs dictated by society: to avoid possible problems and for a future successful career.

A three-point answer scale is used for evaluation: Yes, No, I do not know. Each positive answer adds a point to the poll.

\section{Working Hypothesis}

The use of selected innovative approaches in education, in the field of information communication technologies (ICT) increases the level of motivation of elementary grade pupils from "Aleko Konstantinov" Primary School in their math classes. 


\section{Processing and Analysis of The Results of The Final Experiment}

The survey was conducted for classes in mathematics. The obtained results are presented by subjects and are processed with IBM's SPSS program. In order to indicate the types of surveys, the abbreviations will be used: initial motivation (IM) and motivation when using ICT (MICT).

\section{Mathematics}

The frequency distribution of the results from the survey on the subject "Mathematics" is shown in the following tables.

Table 1: IM

\begin{tabular}{|c|c|c|c|}
\hline & \multicolumn{3}{|c|}{ Freq.PercentValid PercentCumulative Percent } \\
\hline Valid 2,00 7 & 13,5 & 13,5 & 13,5 \\
\hline 3,008 & 15,4 & 15,4 & 28,8 \\
\hline $4,00 \quad 17$ & 32,7 & 32,7 & 61,5 \\
\hline 5,0020 & 38,5 & 38,5 & 100,0 \\
\hline Total 52 & 100,0 & 100,0 & \\
\hline
\end{tabular}

Table 2. MICT

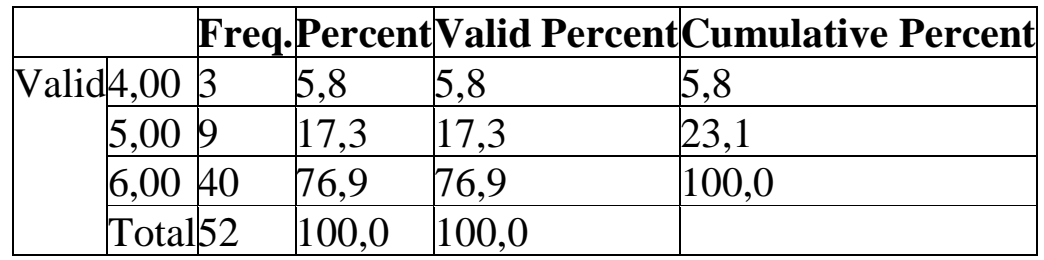

The performed variation analysis generates the following Table 3, where we can see that there is a difference in the average values of the two variants of the performed mathematical surveys $\operatorname{MICT}($ Mean $)-\operatorname{IM}($ Mean $)=1.75$.

Table 2: MICT

\begin{tabular}{|c|c|c|c|c|c|c|c|}
\hline & $\mathbf{N}$ & Range & Minimun & Maximum & Sum & Mean & Std. Deviation \\
\hline & \multicolumn{2}{|c|}{ StatisticStatistic } & Statistic & Statistic & Statisti & Statistic & Statistic \\
\hline IM & 52 & 3,00 & 2,00 & 5,00 & 206,00 & 3,9615 & 1,04715 \\
\hline MICT & 52 & 2,00 & 4,00 & 6,00 & 297,00 & 5,7115 &, 57177 \\
\hline Valid N & & & & & & & \\
\hline
\end{tabular}

\begin{tabular}{|c|c|c|c|}
\hline \multicolumn{2}{|c|}{\begin{tabular}{|c|} 
Skewness \\
\end{tabular}} & \multicolumn{2}{|c|}{ Kurtosis } \\
\hline \multicolumn{4}{|c|}{ StatisticStd. Error Statistic|Std. Error } \\
\hline,- 667 & 330 &,- 732 &, 650 \\
\hline$-1,890$ & 330 & 2,661 & 650 \\
\hline
\end{tabular}

It remains to verify whether this difference is a result of the applied innovative approach or it is random. 


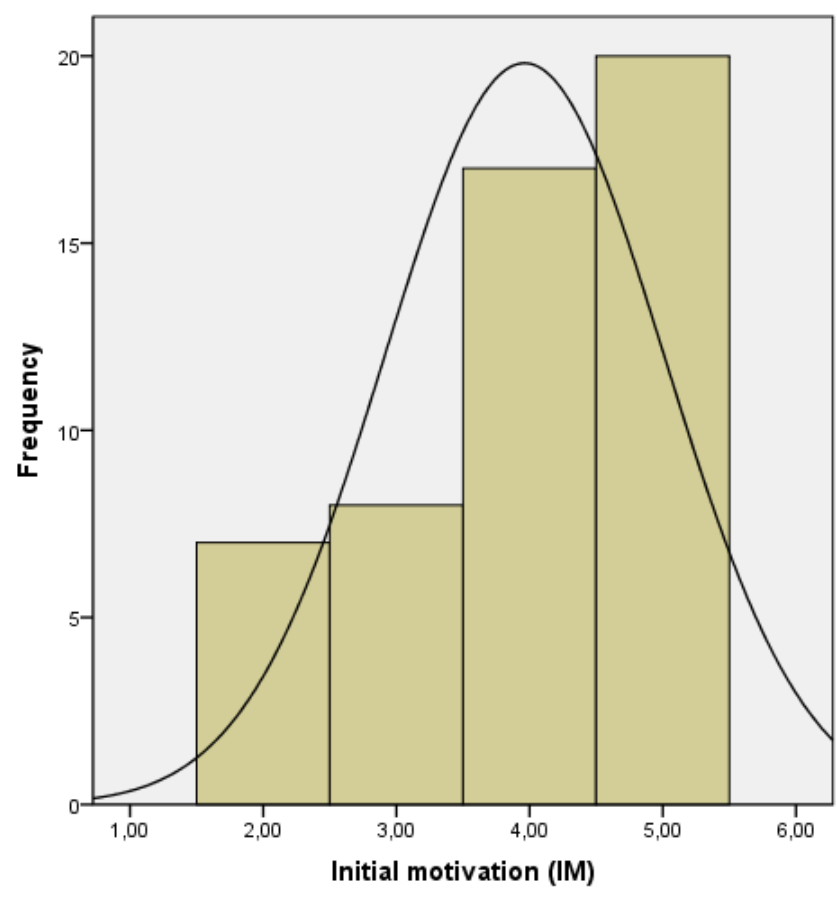
Mean $=3,96$
Std. Dev. $=1,047$

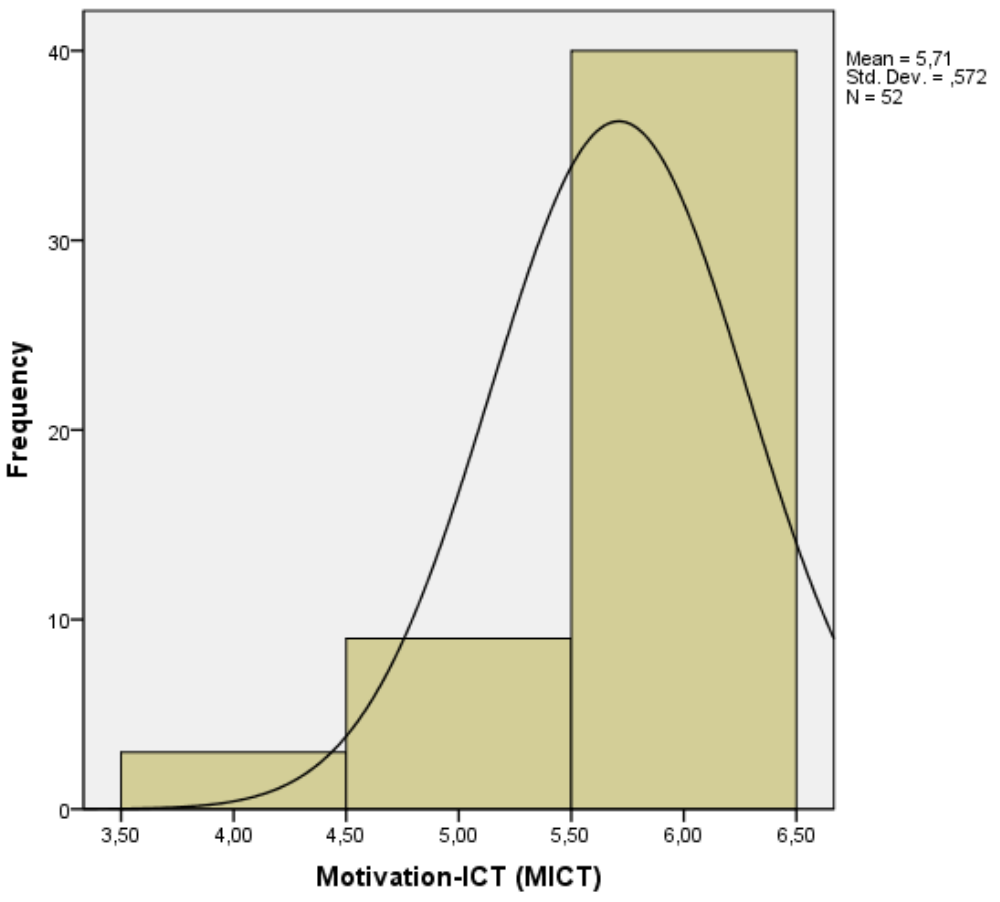

Figure 1: Histograms of a control and an experimental group for task 1

For this purpose, it is necessary to check for a normal distribution of the empirical data of the two variants (IM and MICT), which will determine the choice of a method of comparison. The histograms of the results from the math survey are shown in Figure 1. The tests of KolmogorovSmirnov and Shapiro-Wilk (Table 4) return value for Sig. (degree of significance) of less than 0.05 (0.000), which is a sufficient condition to reject the null hypothesis for a normally distributed 
sample in favour of the alternative hypothesis for the non-normal distribution of the processed results.

Table 4: Test for normal distribution

\begin{tabular}{|c|c|c|c|c|c|}
\hline & \multicolumn{5}{|c|}{ Kolmogorov-Smirnov ${ }^{\mathrm{a}}$ Shapiro-Wilk } \\
\hline & Statistic & dff & Sig. & Statis & cdf Sig. \\
\hline IM & 226 & 52 & 000 &, 823 & 52,000 \\
\hline MICT & {$[, 462$} & 52 &, 000 &, 552 & 52,000 \\
\hline
\end{tabular}

From the conclusions drawn for the distribution of the two results, it is necessary to use a nonparametric method for the comparison of dependent samples.

The comparison of the pair MICT-IM in mathematics is done with the T-test of Wilcoxon (Wilcoxon Signed Ranks Test), where for the Asymp.Sig (2-tailed) (degree of significance) a value of ,000 is obtained (Table 5).

Table 5: The T-test of Wilcoxon

\begin{tabular}{|c|c|c|c|}
\hline \multicolumn{4}{|c|}{ Ranks } \\
\hline & \multicolumn{3}{|c|}{ N Mean RankSum of Ranks } \\
\hline \multicolumn{2}{|l|}{ MICT - IMNNegative Ranks $0^{\text {a }}$} &, 00 &, 00 \\
\hline Positive Ranks & $46^{b}$ & 23,50 & 1081,00 \\
\hline Ties & $6^{\mathrm{c}}$ & & \\
\hline $\begin{array}{ll}\text { Total } \\
\end{array}$ & 52 & & \\
\hline a. MICT< IM b. MICT > & IM & c. $\mathrm{M}$ & $=\mathrm{IM}$ \\
\hline
\end{tabular}

\begin{tabular}{|l|l|}
\hline \multicolumn{2}{|c|}{ Test Statistics } \\
\hline \multicolumn{1}{|c|}{} & MICT-IM \\
\hline$Z$ & $-5,985 \mathrm{a}$ \\
\hline Asymp. Sig. (2-tailed), 000 \\
\hline $\begin{array}{l}\text { a. Based on negative ranks. } \\
\text { b. Wilcoxon Signed Ranks Test }\end{array}$ \\
\hline
\end{tabular}

On the basis of these results (significance level <0.05), it can be concluded that the differences between the average values MICT-IM in mathematics are not random but are the result of applied innovative approaches. In other words, the working hypothesis for the subject "Mathematics" is confirmed.

\section{Conclusions and Evaluation}

1) A pedagogical study was carried out with a representative sample of a total of 52 elementary grade pupils from "Aleko Konstantinov" Primary School, Plovdiv with the aim to specify the change in the students' level of motivation after using selected innovative teaching approaches in the field of ICT; 
2) The obtained results have been assessed by IBM's SPSS software for the analysis of survey results using the Wilcoxon T-test for two dependent samples to reject the assumption of the random nature of the result;

3) On the basis of the above actions and the obtained results, the following conclusions can be drawn:

- The results of the conducted surveys on the subject "Mathematics" show a significant difference in the level of learning motivation;

- The analysis confirms the working hypothesis that the use of selected innovative ICT training approaches (presentations, e-tests, e-learning content and electronic incentives) increases the level of learning motivation in mathematics of elementary grade pupils from "Aleko Konstantinov" Primary School.

\section{Conclusion}

The main hypothesis of the study that the use of selected innovative approaches for ICT training increases the level of learning motivation of elementary grade pupils from "Aleko Konstantinov" Primary School in their Math lessons was confirmed by the results of the performed pedagogical experiment.

The obtained objective information proves the significance of the innovations in the elementary grades of "Aleko Konstantinov" Primary School.

\section{References}

[1] Addwell Chipangura, and Jill Aldridge. (2017). "Impact of multimedia on students' perceptions of the learning environment in mathematics classrooms" Learning Environ Res, 20(121). https://doi.org/10.1007/s10984-016-9224-7

[2] Gordeeva, Sychev, and Osin. (2014). "Academic Motivation Scales" questionnaire" Психологический журнал Российская академия наук, 35(4), 96-107. https://elibrary.ru/item.asp?id=21836182

[3] Ivanova Ralitsa, and Velikova Emilia. (2015). "Modern methods of teaching mathematics" University of Ruse "Angel Kanchev", 54(6.4), 40-45. http://conf.uni-ruse.bg/bg/docs/cp15/6.4/6.44.pdf

[4] Koleva Zhana, Eredzhebova Nevin, and Moldovanova Radost. (2016). "For the new position of children's individuality and the teacher", 3, 96-103.

http://uni-sz.bg/truni4/wpcontent/uploads/pf/file/PEDAGOGICHESKI_FAKULTET/STUDENT_ALM_2016/9_ZhanaKol eva.pdf

[5] Staribratov Ivaylo, and Angelova Evgeniya. (2011). "Teaching Methods and Approaches Using Electronic Learning Resources" National Conference "Education in the Information Society", 329336.

http://sci-gems.math.bas.bg:8080/jspui/bitstream/10525/1560/1/adis-may-2011-329p-336p.pdf

[6] Stavros Nikou, and Anastasios Economides. (2016). "The impact of paper-based, computer-based and mobile-based self-assessment on students' science motivation and achievement" Computers in Human Behavior, 55(B), 1241-1248.

http://conta.uom.gr/conta/publications/PDF/1\%20CHB\%20journal\%20.pdf 
[7] Stoitsov Gencho, and Stoitsova Gergana. (2017). "Virtual instrument for supporting the education in primary school" National Scientific Conference "Education and science - for personal and social development", 75-84.

[8] Zheleva Petya. (2018). "Iimplementation of cloud technologies in education" Education and technologies, 9/2018, 377-382.

http://www.edutechjournal.org/wp-content/uploads/2018/08/2_2018_377-382.pdf

[9] Ilin Evgenii. (2002). "Motivation and personality" Piter. http://files.soyuz-minor.ru/biblioteka/llinmotivaciya-i-motivy.pdf

*Corresponding author.

E-mail address: stoitzov@ abv.bg 